\title{
EEN WOORD OVER WATER EN BODEMBEDERF.
}

't Is zeker, dat de gelden, die nu in een jaar aan doktoren en apothekers worden betaald, heel wat meer nut zouden doen, wanneer zij werden gebruikt voor doeltreffende maatregelen in het belang onzer volksgezondheid. Wel is waar kwam de overtuiging, dat de gezondheidstoestand onzer dicht bebouwde gemeenten veel te wenschen overlaat, in de jongste jaren meer tot rijpheid, maar in lang niet alle Nederlandsche gemeenten wordt voor voldoende afvoer van stedelijk vuil, voor flinke rioleering, voor het verkrijgen van goed drinkwater en wat dies meer zij, gedaan wat gedaan kon en gedaan moest worden. Niet overal is men doordrongen van het gewicht der zaak, - iets, dat echter weêrsproken wordt door de duizend angsten, die uit de duizende voorzorgmaatregelen bij besmettelijke ziekten blijken.

Wie zijn oogen behoorlijk gebruikt en zoo hier en daar in de Nederlandsche steden den toestand der grachten eens opnam, erkent meer en meer het juiste van de teekening, die Dr. Schick in 1852 ophing van de Haagsche modderpoelen en grachten. Die toestand wordt nog in vele steden bestendigd, ten huidigen dage zijn er nog tal van grachten en modderpoelen, "waaruit, met honderd armen, dat dreigend en verslindend monster, wiens adem ziekte en dood is, de woningen indringt."

Reeds in den goeden ouden tijd waren de grachten een voorwerp van de aanhoudende zorg der stedelijke regeeringen. Ten bewijze daarvan kan 0 . a. ook het volgende besluit der gemeente Utrecht dienen.

${ }_{n}$ Des Woensdachs na onser Vrouwendach assumptio, in den jaare 1471.

Alzoe nu tiegenwoerdelich die Vecht van Maersen tot aen Louwenrecht ghedyept is, ende men die zelve Vecht ofte Louwenrecht oick mede dyepen zel, ende die zelve Vecht aldaer te nauwe ende te enge is, ende noi $\left({ }^{*}\right)$ is wyder te maken. Ende want Jan van

(*) d. i. noodig. 
Hamersteyn getoent heeft enen Stat-brief, sprekende van woerde te woerde aldus: ${ } \mathrm{Wy}_{\mathrm{y}}$ Borghermeysteren, Scepenen, Rait ende ghemeyn Oudermans van den ouden Raide, ende van den nywe der Stadt van Utrecht, doen kont ende kenlic allen luden, dat wy, mit goede voerzien ende wel beraden, quytgeschouden hebben, ende quytschelden mit dezen tegenwoerdige brieve, tot behoef Jans van Hamerstein, ende zyne erfnamen ende nacomelinghen, alzulck recht ende toesecgen, als wy ons vermaten te hebben aen dyen aenval van den erve, dat ghelegen is allanges by der ouder Vecht, ende voert alomme by der Vecht ten hoghen lande toe, in Jolinus Gerechte voerscreve, dat hy van der Domproest t'Utrecht te leen hout, ende daar hy ons den lesten peuning mitten yersten vol ende al of betaelt heeft; mit zulken voerwerden, dat onser Stat dyepe ende weteringe alzoe wyt bliven zellen, als zy nu zyn. Ende waer oick dat zake, dat wy, of onse nacomelingen, hyr namaels tot eniger tyt die Vecht van den Weerde $\left(^{*}\right)$ tot ten Moelenwerve totten Hoghenlande wyden wouden, zoe zoude wy nemen aen die westzyde van der Vecht alsulck erve, als wy daer leggende hebben in dezer tyt. Ende waert dat ons dan dochte, dat dyep te enge wezen, zoe mochten wy nemen van Jans lande voerseyt alsoe vele, als den Raide out ende nywe bescheydeliken dochte, zonder archeyt. In oorkonde dezes briefs bezegelt mit onser Stadt zegele. Gegeven int Jaer dusent drie hondert negen en tseventich, op sinte Agnete avont." - Ende want die zelve brief int laeste innehout, of men die Vecht in toekomende tyden wyden zoude, dat men dat nemen zoude van den erven, die die Stadt op die tyt lecgen had aan die westsyde, ende dochte den Raide out ende nywe dan, dat die Vecht niet wyt genoch en waer, alsdan zoude men die wyde nemen aen dander zyde in Louwenrecht, gelyck die brief voerscreve dat vorder innehout: Zoe zyn die Raide out ende nywe overdragen, dat men die Vecht aldaer nu wyden zal, ende die wyde aen beyden zyden van der Vecht nemen zell, daert den Deputaten van der Vecht, mitten Oversten out ende nywe goetduncken zal, ende daer zal een ygelick mede tevreden wezen."

Uit tal van gegevens betreffende het jaar 1471, bleek mij, dat de Oude-gracht in de stad en daarbuiten verdiept werd. Vermelding verdient het, dat de kosten van dit werk niet door "de Stat" gedragen, maar hoofdzakelijk door de burgers gegeven werden; --

(*) d. i. Weerdpoort. 
de stad bekostigde alleen het afdammen en het nithoozen. De verdieping binnen de stad moest door de ingezetenen worden.bekostigd. 't Is licht te bevroeden, dat niet alle Utrechtenaren als slootgravers en baggerlieden konden fungeeren. Het stedelijk bestuur begreep dat later ook, en besloot het werk uit te besteden op koslen ran hien, die daarvoor behoorden bij te dragen; - de onwillige betalers werden bedreigd met de bepaling, dat zij zouden worden nuitgepand." Het dagloon der werklieden werd bepaald op een "stoter"; het graven werd per roede aangenomen.

Natuurlijk moest er plaats gemaakt worden voor de uitgebaggerde specie, doeh die was gemakkelijk te vinden. Den bewoners aan weerszijden der Oude-gracht werd aangezegd, dat zij hunne werven, kelders en kluizen ledig moesten maken voor berging der baggerspecie. Die eigen huizen bewoonden, moesten op eigen kosten voor 't wegbrengen zorgen, maar de bewoners van huurhuizen mochten de halve onkosten van de huurpenningen inhouden. Schouwen en bokken (vaartuigen) werden voor dit doel door de regeering te huur aangeboden. In één zomer liep dit werk af en kostte „42,645 ponden, 19 stuivers en 9 duiten."

Toen dit werk was afgeloopen werd, bij klokgelui, des Saturdags na Victoris, het volgende van het Raadhuis afgelezen:

„Die Raide out ende nywe laten weten ende gebieden enen ygeliken deze nabeschreve punten te bouden ouverbreclich by de koeren diıer op staende.

In den jersten, dit uyemant enyghe eerde noch vulnysse langes der Vecht, tusschen der Stadt ende Muersen op ten Dyck werpen en sel, mer men zel platetzen ordinieren, dicer men die eerde ofte vuylnysse voeren zel. Eude waert zake, dattet hyr boven ymant dede, die zoude verboeren die schouwe, schip ofte bock, diter die eerde ofte vulnysse inne geladen wier, ende men zel duer die schonwe, schip oftc bock, enen pael sliten, ende alzoe laten lecgen, anderen lieden tot enen exempel; ende ditertoe zil die broekige verboeren vijf ponden, hillf totter Stadt behoef, ende dan der helfte totter gheens behoef, die den broekigeu aeubrochte, ende byr van zel een ygelick koermeyster wezen.

Iten, dat nyemant ryden en zel mit peerden lings der Vechte, om scepen ofte bokken op te halen, ofte ueder te voeren, by enen koer van vyf ponden, zoe dicke alst yemant dede; half totter Stadt behoef, ende half totter gheens behoef, die den broekigen aenbrochte, ende hyr van zel een yegelick koermeyster of wezen.

Item, dat nyemant enige asch of vuluysse op ander lude werven, 
noch in die graft werpen en zellen, by cnen koer van vyf pouden, zoe dicke alst jemant dede, balf totter Stadt behoef, ende half totter gheens behoef die dic broekige aenbrochte, ende hyr zcl een yegelick koemneyster of wezeu, ende die broikigen nenbrengeu by zynen eede: ende dic Cameraer zel hem dan zyu aendeel van de broiken voerscreve oplecgen ende betalen, ende den broikigen weder of doen balen op boeren cost. Endc die weerdt vin den huse zel voer zyne kinder ende boden geldeu ende betalen, ende zynen boden weder of corten :Ien zynen loen. Ende waer ymant, die ymant zaghe assche ofte vulnys op die werven of in die graften werpen, ende den broikigen niet aen en brochte, als voersereven staet, ende ment ter waerheit vonde dat hyt gesien ende niet aengebrocht en hadde, die zoude verboeren die voersereve vyf ponden, balf totter Stadt behoef, ende half tot behoef des gleens, die hen dan voert aenbrochte by zynen eede.

Item, dat niemant gheene poen, messen, eoch gheenrehande onreynlicheyt, daer men die Vecht ende graft mede vollen mochte, in enighe scepen ofte schouwen en liden, zy en hebben plancken ofte horden op ten scepen ofte schouwen, aen den werve lecgen, by alzoe dat gheen poen, messen of oureynlicheit in die Vecht ende graft en vallen, by enen koer vau vyf pouden, hitlf totter Stadt behoef en dander helft tottes gheens behoef, die die broikigen aenbrochte, ende hyr van zel een ygelick koermeyster wezen.

Item, dat die Buer, die tot elker brautrappen (brandtrappen) hoeren, die eerde op ten trappen, of ouder den trappen lecgende, wech laten voeren, ende dat roert sueer op ghenen brintrappen, noch onder trappen, aen die graft, noch op ghene bruggen, noch in enyghen wedden, enich balken of ander hout, noch steen, of lasten en lecgen, woch op en trecken mit peerden, of anders, noch enighe asscle ofte vulnysse aldaer en brengen, by enen koer van vyf ponden, zoe dicke ende menichwerre alst ymant dede, half totter Stadt behoef, die die brokigen aenbrochte, eude hyr vin zel een ygelick koermeyster wezen.

Item, dat nyemant enich hout, balken of ander lasten, in die graft en leggen of leegen laten, die den stroem beletten moigen, langer dan drie dighe, by 't verboeren van deu houte, balken ende andere lasten, totter Stadt behoef; ende hyr van zel een ygelick koermeyster wezen.

Item, dat die ghene, die hoer werven ingevallen zyn, hoer werve laten maken, ende die oude palen in der graften ut doen trecken binnen vierthyen diaghen naest komende; of daer en thenden zel die Stadt die werven laten maken. ende die palen ut doen halen, op ter gheenre cost, dien die werve toebehoeren.

Item, dat nyemant enige verkenen en houden op engghe werven, 
noch in gheenre kelren, die ter grafwert utgnen, by enen koer van vyf ponden van elken verken, die men niemant verdragen en.zel; ende hyr van zel een ygelick koermeyster wezen, ende die koeren : half hebben. Ende van allen pusten voerscreve zel men ene cedule utbangen voer der Scepenen huys, op dattet een ygelick weten mach."

Het moet gezegd, dat men in den jare 1471 te Utrecht vrij wat beter tegen vervuiling der grachten waakte dan men in 't jaar onzes Heeren 1883 in tal van Nederlandsche steden doet. Ook het Utrecht van den huidigen dag bewijst, helaas! dat niet op den goeden weg, in 1471 ingeslagen, is voortgegaan; houderden secreetputten monden, door rio'en uit in het water van de Oudeen Nieuwegracht. Echter zal de tijd niet verre meer zijn, dat ook deze slinksche wegen van faecalien-afvoer tot de geschiedenis behooren. Vele steden reeds verboden bij politie-reglement het uitmonden van beerput-riolen in de stadswaters; andere verboden het aanleggen van nieuwe, nog andere geboden in den laatsten tijd het wegruimen van de bestaande onderaardsche mestkuilen.

Ter zake. Wij spraken over grachten en grachtvervuiling en zien ons onwillekeurig voor de vraag gesteld, waaraan toch de grachten der steden wel hun ontstaan hebben te danken. Voorzeker graafde men ze allereerst ten dienste der scheepvaart, om het noodige water, dat de nijverheid vroeg, te bekomen, om bluschwater bij brand te hebben en... om plaatselijk vuil op gemakkelijke wijze af te voeren. Vooral ten behoeve van dit laatste doeleinde der grachten was het vereischte, dat trouw voor waterverversching werd gezorgd. Dat begreep men echter niet, althans er werd voorheen al heel weinig gedaan voor aanvoer van versch en ververscht water. In het vuil maken der grachten was men des te ijveriger. Aanvankelijk bewandelde men daarvoor de meest primitieve, later meer kunstmatige, nog later (en ook heden ten dage) gekunstelde en dikwijls zeer slinksche wegen. In den goeden (!) ouden tijd werden vuilnisbakken, faecale stoffen etc. eenvoudig naar de stadsgrachten gedragen en er in geworpen. Men wane niet, dat dit geheel tot het verleden behoort; ook thans nog ziet men het dikwijls doen, vooral in den avond of des nachts, wanneer men zich veilig waant voor het „bemoeiziek" oog der politie. 't Schijnt een aangeboren $\mathrm{kwaad}$, een erfstuk der vaderen, maar 't is evenwel een feit, dat men liever het vuil naar de grachten brengt, dan het afgeeft aan de lieden, die het op gezette tijden des daags aan de huizen komen vragen. Vloeit dit wellicht voort uit de gehechtheid aan het oude, - een karaktertrek van den 
Nederlander, die zoo gaarne langzaam volgt, in plaats van vooruit te gaan? Hoe het zij, trots al de politie-verordeningen, die het kwaad willen voorkomen en trachten tegen te werken, kunnen er in ieder stad bijna dagelijks bekeuringen worden gedaan over bedoelde feiten.

Die extra primitieve toestand van den ouden dag moest langzamerhand plaats maken voor een verbeterde: het vuil werd door riolen naar de grachten afgevoerd. De verbetering hier bedoeld, bestond natuurlijk uitsluitend in eene vergemakkelijking.

Ook die afvoerkanalen of riolen hebben eene geschiedenis. Er is trouwens in de laatste jaren dikwịls gerept van den voorvaderlijken toestand, waarin de riolen van vele steden nog ten huidigen dage verkeeren. Open riolen, die thans in de meeste steden (o.a. ook in de hoofdstad des rijks) met eene plank overdekt zijn, waren de eerste middelen, die al wat maar eenigszins vloeibaar was, moesten afvoeren. Al heel spoedig begon men echter in te zien, dat die inrichting niet bestendigd mocht worden. De gedurig herhaalde overstroomingen bij overvloedige stortregens, het bevriezen in den winter en vooral de gruwelijke stank, die er uit opstijgt, zijn voldoende redenen tot afkeuring van dit stelsel. Onderaardsche riolen, meende men, zouden aan alle billijke eischen kunnen beantwoorden; in elk geval bevredigden zij het oog en - dacht men - vuil onder den grond zal toch geen kwaad uitwerken! Doch ook bij dit werk roeide men al weer met de riemen, die de techniek van dien tijd ter beschikking had. Niet alleen dat men riolen met platten bodem nam, die een grootere ruimte voor bezinking aanbieden, ook waren de binnenvlakten, waar langs de vloeibare massa zijn weg moest vinden, ruw en daardoor zeer geschikt voor vervuiling. Een grooter kwaad was echter, dat men de riolen te laag lag, om zeker te zijn ran eene gemakkelijke uitwatering. Met den waterstand is bij tal van werken al heel slecht rekening gehouden; - voorzeker zeer raadselachtig voor een land, dat in het water steeds een vijand leerde kennen, tegen wien veel strijds gestreden en om wien veel leeds geleden werd. Als het water der grachten waarin de riolen uitmonden, hoog staat, stroomt het in die riolen. Was dat water zuiver, schoon en frisch, dan kou de uitwerking van die spoeling een zeer weldadige zijn, maar in den regel is het grachtwater bezwangerd met allerlei vuil en gistende zelfstandigheden. Er komt bij, dat het verval der riolen dikwijls zeer gering is; - wij zagen er zelfs, die - hoe onbe- 
grijpelijk! - over eene lengte van ruim 60 Meter nog geen $1 \frac{1}{2}$ d.M. verval hadden. In een der eerste Nederlandsche steden zagen wij dezer dagen een drietal riolen, die al het huis- en keukenvuil van drie vrij groote gezinnen moesten afvoeren, uitmonden in een stilstaand water (een ware modderpoel!) van nog geen $90 \mathrm{M}^{2}$ oppervlakte. Gedurende den ganschen zomer is die mestkuil niet geruimd, omdat... ja, eigenlijk, omdat men bet er niet over eens was, wie zich met de lediging moest belasten: òf het gemeentebestuur of de eigenaar van de drie woningen, die het vuil er in loosden en er onmiddelijk aan grenzen.

En zoo zouden wij kunnen voortgaan met een reeks van gebreken der rioleering op te sommen (men denke nog aan de specie waaruit de riolen meestal zijn gebouwd), maar het bovenstaande bewijgt voorzeker op afdoende wijze, dat men met rioleering steeds vrij onbezonnen te werk ging. Aan onkunde op bouwkundig gebied zal toch wel niemand al die feilen willen wijten; - althans andere bouwwerken (boven den grond) van dien tijd geven gunstiger getuigenis van de bouwkunde dier dagen. Wellicht, dat men al heel slecht rekening hield met de plaatselijke toestanden, alle plaatsen "over een kam schoor" en te veel vergat, dat een rioleering-plan, dat voor de eene gemeente doelmatig is, voor eene andere niet altijd kan worden aanbevolen.

In 't algemeen moet er bij den aanleg van riolen op gelet worden, dat men het werk aan bekwame personen opdraagt, personen, die op dat gebied de sporen hebben verdiend.

De vorm zij zoodanig, als meest dienstig is voor den afvoer van den inhoud, nl. met kleine bedding. Allermeest wordt dien vorm verkregen door een ronden of eironden bodem te maken.

De inhoudsruimte der riolen verdient mede rijp beraad, eer men tot den aanleg overgaat. $\mathrm{Er}$ moet daarbij met zooveel rekening worden gehouden. 't Spreekt als van zelf, dat de inhoudsruimte evenredis moet zijn aan het volume der af te voeren speciën, maar bij de berekening dier ruimte worden tal van gegevens gevorderd. Het aantal woningen, dat er zich van zal bedienen, het gemiddeld waterverbruik der bewoners, de gemiddelde hoeveelheid regenwater, die er in zal kunnen stroomen en tal van andere gegevens, gewijzigd naar omstandigheden, zijn bij die berekening noodig.

De hoegrootheid van het verval dient $0 . \mathrm{m}$. a. ook geregeld naar de hoeveelheid spoelwater, waarover men kan beschikken en naar bijkomende invloeden, die den loop der rioolstoffen kunnen bevorderen en tegenwerken.

ECoN. 1883. 
De bouvostoffen voor de riolen moeten vooral deugdelijk zijn, bestand tegen de inwerking van de zuren der vervoerde stoffen; en warborg leveren, dat de wanden niet licht zullen scheuren.

Vooral de vraag of de te leggen riolen waterdicht zullen zijn, verdient rijpe overweging. Pettenkofer, iemand, die over riolisatio mee kon spreken, beweerde, dat riolen, vervaardigd van metselwerk en cement en waarvan de binnenwanden met asphalt zịnn bestreken, waterdicht kunnen zijn (Asphalt wordt niet door de riool-zuren aangetast). Onderzoekingen van lateren datum, ook in onderscheidene Nederlandsche steden, hebben bewezen, dat de waterdichtheid zeer wel te verkrijgen is.

't Ligt echter geenszins op onzen weg en evenmin binnen de grenzen van ons bestek, het technische deel der rioleering hier na to gaan; dat is het werk der vakmannen. De belangrijke vraag, die hier een antwoord vraagt, is: waarvoor worden de riolen gebezigd? Voor al het vuil, dat uit huis en keuken moet verwijderd alsmede voor den afvoer der faecale stoffen, of voor een dier beide zaken?' 't Behoeft voorzeker geen betoog, dat riolen, die ook dienen tot faecaliën-afvoer, gevaarlijker zijn voor de gezondheid der ingezetenen, dan die waardoor alleen ander huiselijk vuil wordt verwijderd. Trouwens iedere rioolsoort vereischt afdoende maatregelen, om niet slecbts de ontwikkeling der gassen tegen te gaan, maar ook te zorgen voor het onschadelijk maken. Niet enkel om het minder aangename der rioolstank, maar allermeest om zeer waarschijnlijke ziekte-oorzaken weg te nemen, is dit vereischte. Evenwel zoekt men nog ten huidigen dage naar een afdoend middel om de ontwikkeling der gassen te voorkomen. Het beste middel is voorzeker: zorg, dat de afvoer door de riolen zoo suel mogelijk geschiede!

Aan raadgevingen heeft het, ook op dit gebied nimmer ontbroken, doch.... goede raad is duur! Het brengen eener groote hoeveelheid water in de riolen, tot doorspoeling en verdunning der stoffen is geen afdoend, geen beslissend middel tegen het kwaad. Ook was men er op uit, om door verbranding; de werking der rioolgassen te dooden. Anderen maakten ventilatie-kokers, voorzien van desinfectie-stoffen. Weer anderen wilden kunstmatige opzuiging van de rioolgassen en dus slechts verplaatsing der schadelijke gassen van uit de woning naar de buitenlucht.

Tegen het rioolstelsel van den bekenden technicus Charles Liernur, zijn vroeger en later heel wat stemmen opgegaan, voornamelijk omdat men de kosten van aanleg vreest, die echter, 
volgens Liernur - en wie toch kan de berekening beter maken dan de ontwerper zelf? - volstrekt niet zoo hoog zijn. Dit stelsel, voor zoover het den afvoer van huis- en keukenafval betreft, heeft bet groote voordeel, dat de afgevoerde rioolvochten alleen nog vuil in opgelosten staat bevatten. Er mogen zich, evenals dit bij ieder nieuw plan het geval is, tal van stemmen tegen verheffen, ongetwijfeld heeft dit stelsel eene toekomst.

Maar waar blijven de stoften, die de riolen afvoeren?

Ziedaar eene vraag, dis reeds roor eeuwen gedaan is en waarop heden ten dage nog een even beschamend antwoord moet worden gegeven als voor vele jaren. Hchben enkele steden in latere jaren begrepen, dat het op hunnen weg ligt den landbouw te dienen met alle mogelijke mestspeciën, die eenige stad oplevert, in tal van andere plaatsen (groote en kleinere) bekommert men zich daarover al bitter weinig. "Voor eeuwen", zegt Liebig, "hebben de riolen van het oude Rome (die de faecale stoffen niet aan den landbouw teruggaven, maar nnar den Tiber on verder naar zee afvoerden) de welvaart van den Romeinschen boer verzwolgen, en, nadat de uitgeputte velden rondom Rome nagenoeg niets meer konden opbrengen, werden zij oorzaak der uitputting van de velden der eilanden Sardinie en Sicilie en van de vruchtbare noordkust van Afrika." In den loop der tijden zijn tal van maatregelen genomen, om de in grachten en rivieren afgevoerde rioolstoffen daaruit weder te vergaren en het gracht- of rivierwater daarvan te ontdoen. Maar die pogingen leden schipbreuk. In Engeland verbood men reeds voor jaren het later uitmonden van riolen in de rivieren en binnenwateren.

Vele Nederlandsche steden die den afvoer door riolen naar te grachten beletten, bedienen zich tegenwoordig van zoogenaamde zinkputten of vervalgaten. Is daarmede niet in elk opzicht voldaan aall eene doelmatige verwijdering der rioolstoffen en wordt van die zinkputten veel misbruik gemaakt, daar de ingezetenen (vooral in de achterbuurten) al hun vuil daarin deponeeren, - bij geregelde uithaling eu desinfectie zijn deze reservoirs voorzeker een stap in de goede richting, en mogen dan ook voor 't flink uithalen en reinigen dier reservoirs geen kosten te groot worden geacht. Vooral moeten, met het oog op den gezondheidstoestand der bevolking, de uitgehaalde rioolstoffen niet, zooals veelal geschiedt, slechts een eind weegs worden verplaatst, door ze op een aangegeven punt binnen den kom der gemeente in zoogenaamde legschuiten over te storten. Deze legschuiten worden dan meestal 
eens per dag, of om den anderen dag verwisseld. Dergelijke verplaatsing, waarbij, door de voortdurende omwerking, de rioolgassen vrịlijk kunnen ontsnappen en de omgeving verontreinigen, schaadt meer dan zij baat. 't Geneesmiddel is hier erger dan de kwaal. Toch ziet men het in bijna alle plaatsen. Zal het uithalen ' $t$ beoogde doel nabij komen, dan dienen de schuiten, waarin de rioolstofen worden gestort, buiten den bebouwden kring der gemeente gestort. In vele steden was men daarop reeds voor eeuwen bedacht; voor verzameling van allerlei vuil werd een bepaald terrein buiten de gemeente aangewezen. Zoo vonden wij o. a. van 't bestuur der gemeente Utrecht een besluit uit den jare 1474, dat luidt als volgt:

${ }_{n}$ Die Rait laet weten eenen ygelyke, dat die Stat ene greft heeft doen greven, by der houten brugge, dair men overgaet ten Carthuseren, doer welke greeft een ygelich zine.vulnisse eude onreynlicheit zel moigen doen voeren op ter Stat erve dair thende gelegen. Dairom verbiet die Rait enen ygelicken, dat niemant enige vulnisse ofte onreynlicheit ergent anders langes die Vecht, noch langes den Ryn, en brenge, noch op dio werve en werpe, dan op die voirscreve plaetse, ende dair zellen zij die vulnisse ofte onreynlicheyt ophouden, of op doen houden, by enen koer van vijf ponden, utgesondert, dat een ygelick zine vulnisse wel brengen zell moigen int Veen, off op zyn zolfs erve, zonder verboeren."

Vanwaar toch het verschijsel, dat in onze dagen zooveel $z$. g. stadspompen het waarschuwend opschrift dragen: ,ongeschikt roor drinkwater?" Bezwaarlijk is daarvoor eene andere oorzaak te vinden dan verontreiniging van deu bodem, waardoor eene behoorlijke filtratie wordt verhinderd, terwijl bet een feit is, dat die verontreiniging toeneemt met den ouderdon en de uitbreiding eener stad. Door de luttele zorg, die men voorheen aan den afvoer der faecaliën besteedde, is de bodem der meeste steden verontreinigd door vuil, dat uit slordig gebouwde beerputten (beerkuilen) en vervuilde riolen drong en ook het drinkwater bedierf. Het is van algenneene bekendheid, dat de stadspompen in den regel op ruime terreinen, pleinen enz. zijn geplaatst, waar toch geene beerputten in de oumiddelijke nabijheid zijn. En als nu die pompen zoo verontreinigd zijn, hoe zal het dan wel gesteld zijn met andere welwaterpompen, die nabij beerputten zijn gelegen? Wel is waar worden in de meeste steden maatregelen genomen om toch vooral te maken, dat to bouwen beerputten waterdicht zijn, maar ook daarvoor is 
het beste toezicht dikwerf nog zeer onvoldoende. De zoogenaamde waterdicht gemetselde beerputten verliezen aan het einde van den bouw gewoonlijk een paar steenen (of meer!) uit de zijwanden; dit geschiedt natuurlijk zonder dat derden daarmedo gemoeid worden! Eene put, die op die wijze is gebouwd, is natuurlijk weinig beter de z. g. gestapelde beerputten, waarbij de zijwanden eenvoudig uit op elkander gestapelde steenen (zonder verbinding door metselspecie) bestaan en waarbij aan het leggen van een vloer of bodem niet eens gedacht is. Dergelijke beerputten zijn uitsluitend dienstig voor opname van de vaste deelen der faecaliën; de vloeibare deelen zoeken hun weg buiten de wanden der put en zijn uitgezochte middelen voor bodembederf.

Wị willen ons hier niet mengen in het roor en tegen van het Liernurstelsel. Dat dit stelsel niet meer algemeenen bijval vindt, is geenszins te wijten aan ondoelmatigheid of onbruikbaarheid, maar meer aan de geringe finantieele uitgaven, die de gemeentebesturen disponibel stellen voor een flinken afvoer van vuil. Waar men eene gemeentereiniging organiseerde met het ideaal ngoud uit vuil te slaan", daar zal het Liernurstelsel niet licht ingang vinden. 't Is voorzeker diep te betreuren, dat op vele plaatsen de invoering van het Liernurstelsel vooreerst op finantieele bezwaren afstuit. Aller oog is thans op de hoofdstad des Rijks gevestigd! Wat men ook bewere van het Liernurstelscl, het is zeker, dat zich geen rationeeler manier van vuil-afvoer laat denken dan de pneumatische verwijdering.

Tal van steden beginnen in de laatste jaren het tonnenstelsel in te voeren, - sommige steden stellen die wijze van afvoer der faecaliën zelfs verplichtend. In 1877 geschiedde dit te Franeker, waar de ingezetenen met dien maatregel hartelijk zijn ingenomen en de gezondheidstoestand veel beter is geworden. Voor eenige weken heeft de gemeente Alkmaar het voorbeeld van Franeker gevolgd. Hulde aan de mannen, die dergelijke ingrijpende maatregelen durven nemen in het belang der volksgezondheid, trots een publiek, dat dikwijls uit de hoogte veroordeelt zonder te kennen! Er zijn dan ook heel wat voordeelen op te noemen, die dit stelsel boven het beerputten-systeem verheffen.

Allereerst is het zeer gemakkelijk dit stelsel in to voeren en, zoo noodig, nit te breiden. Wanneer men daarbij begint net deugdelijk materieel te nemen (Amerikaansch-greenen-houten tonnen met roodkoperen randen, waarin gedraaid houten deksels sluiten) en voor voldoende reiniging en desinfectie zorgt, dan levert dit 
stelsel geen finantieële bezwaren op, daar er zeer geringe kosten van onderhoud vereischt worden.

Een ander (grooter) voordeel van het tonnenstelsel is, dat het vervuiling van den bodem onmogelijk maakt, daar de faecaliën niet onder maar boven den grond worden verzameld.

Ook mag niet uit het oog verloren, dat het van groot belang is, dat de faecaliën in verschen tonstand uit de woning worden gebracht. Dan heeft de rotting der stoffen nog niet plaats gehad, zoodat der gezondheid van de bewoners geen nadeel wordt toegebracht. Er komt bij, dat de faecale stoffen in verschen toestand de grootste waarde als meststoffen hebben; in onzen tijd, nu men meer en meer de waarde van mest leert kennen, mag dit niet vergeten.

En zoo zonden wij kunnen voortgaan met de voordeelen van het tonnenstelsel op te sommen; men denke b. v. nog aan de gemakkelijke wijze waarop gebreken ontdekt en verholpen kunnen worden.

Het is waar, dat het bij dag verwisselen der privaattonnen voor onzen preutschen tijd weinig aantrekkelijks heeft, maar het is even zcker', dat de weldenkenden liever hunne gezondheid zien bevorderd door het tonnenstelsel dau dat zij die zien bedreigd door beerkuilen. Beerkuilen of beerputten - wij komen er voor de "beerput-vrienden" nog eens op terug - kunnen bruikbaar zijn, maar dan moet met de drie volgende eischen rekening worden gehouden: waterdichtheid, geen gasontwikkeling in de woningen, en gedurig herhaalde, volledige, stankvrije lediging. Wauneer men een niet al to poreuze steensoort neemt en daarvan in sterke tras de steens- of anderhalf-steens muur opmetselt, terwijl men van binnen een laag cement aanbrengt en de put omringt met een laag flink aangestampte klei (van $\frac{1}{2}$ Meter dikte), dan kan men aannemen een waterdichte beerput te bezitten. Zoodanige putten kunnen op onschadelijke wijze worden geruimd door pneumatische toestellen, die daarvoor bij de meeste gemeentereinigingen aanwezig zijn.

Eindelijk. Waar de politie-verordeningen tegen water- en bodembederf moeten waken, daar is het noodzakelijk, dat die verordeningen vooral in den beginne met kracht worden gehandhaafd! In onzen tijd, nu in het Oosten de gevreesde cholera woedt, zij men toch op z'n hoede!

Ook de gemeentebesturen hebben, door de onrust der gemoederen of de vrees voor besmettelijke zielsten, te schooner kans om 
de algemeene goedkeuring in te oogsten, wanneer zij thans de koe bij de horens pakken. De mannen der techniek en die der hygiène moeten hierbij hand aan hand gaan. Zoo dikwijls toch ontbreekt het aan gemeen overleg, zoodat de plannen, die ont. worpen worden, afstuiten op de overdrijving, die een oppervlakkige blik er reeds in ontwaart. Wanneer technici en hygiènisten hun gezichtskring een weinig wilden verwijden en eenigszins over de grenzen hunner werkkring zagen, zouden meer verbeteringen tot stand worden gebracht. Het beweren, dat men met de finantieële zijde eener zaak niet heeft te maken, als men de zaak werkelijk in ' $t$ algemeen belang acht, getuigt van de zucht, om zich van het hoofdbezwaar van zoo menig plan af te maken of wel om een verwijt over ' $t$ onuitvoerbare der voorstellen te ontgaan. Neen, èn met de technische èn met de finantieele èn met de oeconomische bezwaren moet bij bedoelde plannen rekening worden gehouden.
Utreclth, Juli '83.
G. RENKEMa, Ezn. 